CZASOPISMO INŻYNIERII LĄDOWEJ, ŚRODOWISKA I ARCHITEKTURY JOURNAL OF CIVIL ENGINEERING, ENVIRONMENT AND ARCHITECTURE JCEEA, t. XXXIII, z. 63 (1/II/16), styczeń-marzec 2016, s. 99-108

\author{
Katarzyna MARKOWSKA-LECH ${ }^{1}$ \\ Wojciech SAS ${ }^{2}$ \\ Katarzyna GABRYŚ \\ Mariusz LECH ${ }^{4}$ \\ Emil SOBÓL ${ }^{5}$
}

\title{
WYZNACZANIE WSPÓŁCZYNNIKA POISSON'A NA PODSTAWIE POMIARU PRĘDKOŚCI FAL AKUSTYCZNYCH
}

\begin{abstract}
Współczynnik Poisson’a określany na podstawie prędkości fali podłużnej i poprzecznej jest stosowany w geofizyce jako jeden z parametrów charakteryzujących odkształcenie materiału. W laboratoriach geotechnicznych również prowadzone są badania z wykorzystaniem prędkości fal sejsmicznych, dlatego Autorzy podjęli próbę przeniesienia zależności znanych z teorii sprężystości na ośrodki gruntowe w celu wyznaczenia współczynnika Poisson’a. Praca zawiera wartości współczynnika Poisson'a otrzymane z badań naturalnych gruntów spoistych dwiema różnymi technikami: $\mathrm{w}$ aparacie trójosiowym wyposażonym $\mathrm{w}$ piezoelementy typu bender oraz w kolumnie rezonansowej.
\end{abstract}

Słowa kluczowe: piezoelementy, prędkość fali poprzecznej, prędkość fali podłużnej, kolumna rezonansowa, współczynnik Poisson'a, grunty spoiste

\section{Wprowadzenie}

Współczynnik Poisson'a jest ważnym parametrem wykorzystywanym do przewidywania zachowania się ośrodka oraz w modelowaniu numerycznym [1]. W ostatnich latach w laboratoriach geotechnicznych zyskały na popularności badania z wykorzystaniem prędkości fal sejsmicznych w gruntach, dlatego Autorzy podjęli próbę wyznaczenia współczynnika Poisson'a na podstawie zależności znanych z teorii sprężystości. Tradycyjnie rozróżnia się dwie metody okre-

\footnotetext{
${ }^{1}$ Autor do korespondencji/corresponding author: Katarzyna Markowska-Lech, Wydział Budownictwa i Inżynierii Środowiska SGGW, Laboratorium - Centrum Wodne, ul. Ciszewskiego 6, 02-776 Warszawa, tel. 22-59-35-227, katarzyna_markowska_lech@sggw.pl

${ }^{2}$ Wojciech Sas, Wydział Budownictwa i Inżynierii Środowiska SGGW, Laboratorium - Centrum Wodne

${ }^{3}$ Katarzyna Gabryś, Wydział Budownictwa i Inżynierii Środowiska SGGW, Laboratorium-Centrum Wodne

${ }^{4}$ Mariusz Lech, Wydział Budownictwa i Inżynierii Środowiska SGGW, Katedra Geoinżynierii

${ }^{5}$ Emil Soból, Wydział Budownictwa i Inżynierii Środowiska SGGW, Katedra Geoinżynierii
} 
ślania tego parametru: "statyczny" współczynnik Poisson'a (v) określany jako stosunek odkształceń bocznego (radialnego) i osiowego powstałych pod wpływem przyłożonego obciążenia:

$$
v=\frac{\mathrm{d} \varepsilon_{3}}{\mathrm{~d} \varepsilon_{1}}
$$

gdzie: $\varepsilon_{1}$ - odkształcenie osiowe próbki,

$\varepsilon_{3}$ - odkształcenie boczne próbki,

oraz ,dynamiczny” współczynnik Poisson'a $\left(v_{\text {dyn }}\right)$ obliczany na podstawie pomiarów prędkości fal sejsmicznych ze wzoru [1]:

$$
v_{\mathrm{dyn}}=\frac{0,5 \cdot\left(\frac{\mathrm{V}_{\mathrm{P}}}{\mathrm{V}_{\mathrm{S}}}\right)^{2}-1}{\left(\frac{\mathrm{V}_{\mathrm{P}}}{\mathrm{V}_{\mathrm{S}}}\right)^{2}-1}
$$

gdzie: $\rho$ - gęstość objętościowa gruntu,

$\mathrm{V}_{\mathrm{s}}$ - prędkość fali poprzecznej,

$\mathrm{V}_{\mathrm{p}}$ - prędkość fali podłużnej.

Niniejsza praca dotyczy określania „dynamicznego” współczynnika Poisson'a $\left(v_{\text {dyn }}\right)$ na podstawie badań w aparacie trójosiowym z piezoelementami typu bender i kolumny rezonansowej. Pomiary prędkości fal, zaliczane do badań „nieinwazyjnych” i ,nieniszczących”, wykonywane są w trakcie innych konwencjonalnych badań, co zmniejsza koszty oraz przyspiesza badania [2, 3]. Na podstawie pomiarów rzeczywistych prędkości fal sejsmicznych można ocenić błąd popełniany przy szacowaniu wartości początkowego modułu odkształcenia (modułu Younga, $\mathrm{E}_{0}$ ) przy założeniu współczynnika Poisson'a równego 0,5.

Do opisu odkształcenia gruntu używane są wskaźniki ściśliwości lub moduły odkształcenia. Dla bardzo małych odkształceń stosuje się początkowy moduł odkształcenia $\left(E_{0}\right.$ lub $\left.E_{\max }\right)$ lub moduł odkształcenia postaciowego $\left(G_{0}\right.$ lub $\left.G_{\max }\right)$. Wielkości te, przy znajomości współczynnika Poisson'a, można określić na podstawie pomiaru prędkości fal poprzecznej $\left(\mathrm{V}_{\mathrm{s}}\right)$ i podłużnej $\left(\mathrm{V}_{\mathrm{p}}\right)$ ze wzorów:

$$
\begin{aligned}
& \mathrm{E}_{0}=2 \cdot \rho \cdot \mathrm{V}_{\mathrm{S}}^{2}(1+v) \\
& \mathrm{G}_{0}=\rho \cdot \mathrm{V}_{\mathrm{S}}^{2}
\end{aligned}
$$

Ze względu na bardzo małe odkształcenia wywoływane w gruncie przez fale akustyczne wyznaczane moduły traktowane są jako sprężyste parametry gruntu. Konsekwencją tych założeń oraz techniki wykonywania badań (ośrodek w pełni nasycony, warunki bez odpływu, brak nadwyżki ciśnienia wody w porach) jest przyjmowanie $w$ obliczeniach początkowych wartości modułu odkształcenia współczynnika Poisson’a równego 0,5 - jak dla materiału nieściśliwego. 


\section{Materiał badawczy}

Badania zaprezentowane w niniejszym artykule wykonane zostały w aparacie trójosiowym oraz kolumnie rezonansowej, na próbkach różnych gruntów naturalnych o nienaruszonej strukturze (NNS). Badania w aparacie trójosiowym przeprowadzono na prekonsolidowanych gruntach spoistych zalegających na terenie Warszawy (próbki P1-P10). Materiałem wykorzystanym w badaniach w kolumnie rezonansowej był piasek ilasty (clSa) pobrany

z poletka doświadczalnego zlokalizowanego w okolicy zrealizowanej trasy ekspresowej S2, między węzłami „Konotopa-Lotnisko" (próbka P11). Na rysunku 1 i w tabeli 1 zaprezentowano krzywe uziarnienia oraz właściwości fizyczne badanych gruntów.

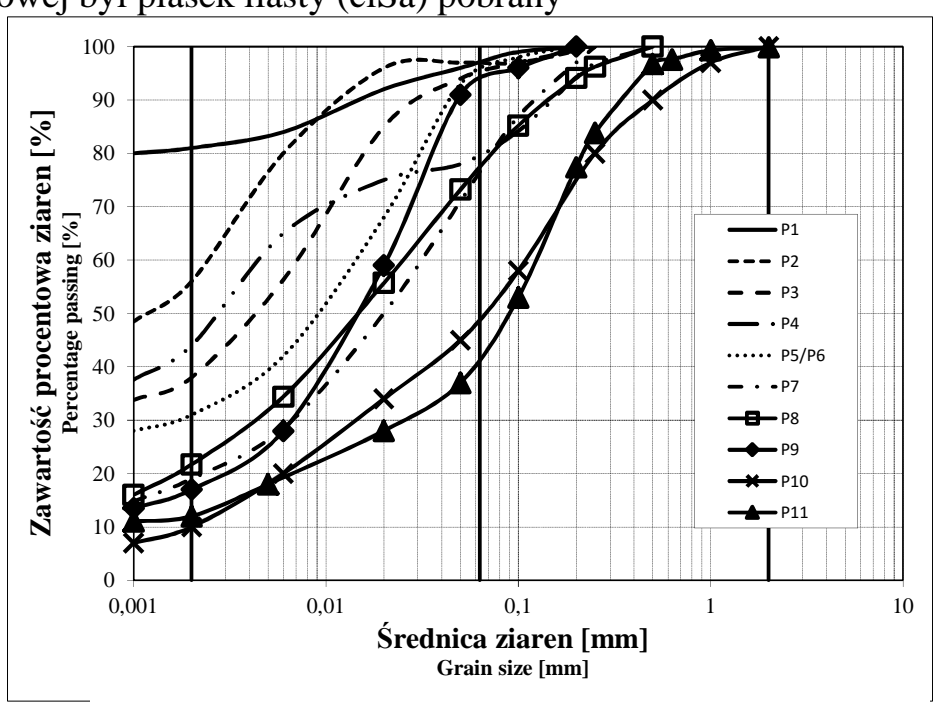

Rysunek 1. Krzywe uziarnienia badanych gruntów Figure 1. Grain size distribution of tested soils

Tabela 1. Właściwości fizyczne badanych gruntów

Table 1. Index properties of tested soils

\begin{tabular}{|c|c|c|c|c|c|c|c|c|c|c|}
\hline & \begin{tabular}{c} 
Głębokość \\
\cline { 2 - 11 }
\end{tabular} & $\begin{array}{c}\text { Nazwa } \\
\text { gruntu }\end{array}$ & $\mathrm{cl}$ & $\mathrm{w}_{\mathrm{n}}$ & $\mathrm{w}_{\mathrm{L}}$ & $\mathrm{w}_{\mathrm{p}}$ & $\mathrm{I}_{\mathrm{p}}$ & $\mathrm{I}_{\mathrm{L}}$ & $\mathrm{p}^{\prime}$ & $\Delta \mathrm{e}$ \\
\hline P1 & $17-17,4$ & $\mathrm{Cl}$ & 81 & 27,7 & 88,1 & 27,5 & 60,6 & 0,003 & 450 & $0,72-0,702$ \\
\hline P2 & $13-13,7$ & $\mathrm{Cl}$ & 56 & 32,5 & 77,2 & 30,1 & 47,1 & 0,05 & 300 & $0,713-0,635$ \\
\hline P3 & $18-18,35$ & $\mathrm{siCl}$ & 38 & 21,7 & 61,1 & 20,1 & 41 & 0,04 & 300 & $0,552-0,471$ \\
\hline P4 & $14-14,4$ & $\mathrm{saCl}$ & 44 & 30,3 & 66,8 & 31,6 & 35,2 & $-0,04$ & 300 & $0,82-0,75$ \\
\hline P5 & $12-12,6$ & $\mathrm{siCl}$ & 31 & 36,8 & 85,8 & 32,2 & 33,6 & 0,09 & 300 & $0,796-0,59$ \\
\hline P6 & $12-12,6$ & $\mathrm{siCl}$ & 31 & 36,8 & 85,8 & 32,2 & 33,6 & 0,09 & 250 & $0,81-0,75$ \\
\hline P7 & $2-2,4$ & $\mathrm{sasiCl}$ & 19 & 26,3 & 36,4 & 18 & 18,4 & 0,45 & 300 & $0,98-0,86$ \\
\hline P8 & $17-17,5$ & $\mathrm{sasiCl}$ & 22 & 22,1 & 36,9 & 18,6 & 18,3 & 0,2 & 500 & $0,697-0,439$ \\
\hline P9 & $14-14,5$ & $\mathrm{siCl}$ & 17 & 22,5 & 36,9 & 18,6 & 18,3 & 0,21 & 330 & $0,65-0,61$ \\
\hline P10 & $3-3,7$ & $\mathrm{sasiCl}$ & 10 & 12,05 & 26,5 & 9,9 & 16,6 & 0,13 & 350 & $0,37-0,34$ \\
\hline P11 & 2,0 & $\mathrm{clSa}$ & 12 & 14,0 & 33,51 & 14,5 & 19,1 & $-0,03$ & 100 & 0,38 \\
\hline
\end{tabular}




\section{Metodyka badań w aparacie trójosiowym}

Badanie obejmowało trzy podstawowe etapy: nasączanie, konsolidację i ścinanie. Konsolidacja prowadzona była etapowo w warunkach izotropowych. Na każdym etapie badania kontrolowano zmianę wysokości próbki oraz wykonywano pomiary prędkości fali poprzecznej $\left(\mathrm{V}_{\mathrm{s}}\right)$ i fali podłużnej $\left(\mathrm{V}_{\mathrm{p}}\right)$.

Pomiar prędkości fal sejsmicznych umożliwiały przetworniki typu bender, zbudowane z piezoceramicznego materiału, który zamienia energię mechaniczną (drgania) na energię elektryczną (impuls) i na odwrót. Wysłane przez generator fal impulsy elektryczne, powodowały drgania nadajnika, które przenoszone dzięki sprężystym właściwościom gruntu, docierały do odbiornika gdzie były zamieniane na impuls elektryczny. Pomiar prędkości fal prowadzony był dla różnych wartości naprężenia efektywnego. Podczas każdego pomiaru analizowany był zarówno wysyłany jak i odbierany sygnał; porównywano częstotliwości i amplitudy tych sygnałów. Szczegółowy opis aparatury i metodyki badań można znaleźć w pracach $[4,5,6,7,8,9,10,11]$.

Prędkość fal rozchodzących się w gruncie obliczana była z zależności:

$$
V=\frac{h}{t}
$$

gdzie: $\mathrm{h}$ - odległość pomiędzy nadajnikiem i odbiornikiem czyli wysokość próbki pomniejszona o głębokość wciśnięcia piezoelementów w grunt $[4,7]$,

$\mathrm{t}$ - czas przejścia fali przez badany grunt.

Dynamiczny współczynnik Poisson'a $\left(v_{\text {dyn }}\right)$ wyznaczono dla kilku próbek, przy różnym naprężeniu efektywnym, $\mathrm{z}$ wykorzystaniem prędkości fal poprzecznej i podłużnej wg wzoru (2) a wyniki obliczeń zostały zamieszczone w tabeli 3 .

\section{Metodyka badań w kolumnie rezonansowej}

Dynamiczny współczynnik Poisson'a można wyznaczyć $\mathrm{z}$ badań $\mathrm{w}$ kolumnie rezonansowej. Badanie w tym aparacie jest uznawane za metodę referencyjną określania sztywności gruntu w zakresie małych oraz średnich odkształceń [8]. Opis aparatury i metodyki badań można znaleźć w pracach [12, $13,14,15]$. Ostateczna formuła na określenie współczynnika Poisson'a $\left(v_{\text {dyn }}\right)$ na podstawie badania w kolumnie rezonansowej jest następująca [12, 13]:

$$
v=\frac{1}{2} \cdot \frac{V_{r o d}^{2}}{V_{S}^{2}}-1
$$


gdzie: $V_{\text {rod }}$ - prędkość fali podłużnej w ograniczonym medium.

$\mathrm{V}_{\text {rod }}$ można wyrazić przy pomocy zależności:

$$
V_{\text {rod }}=\sqrt{\frac{E_{f l e x}}{\rho}}
$$

gdzie: $\mathrm{E}_{\text {flex }}$ - moduł odkształcenia wyznaczany z drgań zginających podczas wykonywania kalibracji urządzenia,

$\rho$ - gęstość objętościowa gruntu.

Prędkość fali poprzecznej $\left(\mathrm{V}_{\mathrm{S}}\right) \mathrm{w}$ kolumnie rezonansowej obliczana jest $\mathrm{z}$ równania:

$$
V_{S}=\frac{2 \pi \cdot f \cdot l}{\beta}
$$

gdzie: f - częstotliwość rezonansowa układu otrzymywana z badania rezonan sowego,

1 - długość badanej próbki gruntu,

$\beta$ - parametr zależny od relacji pomiędzy polarnym momentem bez władności próbki (I), a polarnym momentem bezwładności układu napędowego urządzenia $\left(\mathrm{I}_{0}\right)$.

Do wyznaczenia i analizy współczynnika Poisson'a z badania w kolumnie rezonansowej wykorzystano trzy próbki tego samego gruntu P11, oznaczone dodatkowo literami A, B i C. Po nasączeniu próbek i ich skonsolidowaniu przystąpiono do zasadniczych badań dynamicznych. Wykonane badania realizowane były przy różnym napięciu przykładanym na cewki układu elektromagnetycznego, zmieniającym się w zakresie od $0,1 \mathrm{~V}$ do $0,9 \mathrm{~V}$. W kolejnych seriach badań otrzymywano zmienne wartości częstotliwości rezonansowej $\left(\mathrm{f}_{\mathrm{r}}\right)$. Różnicowano także wartość średniego naprężenia efektywnego (p'). Szczegółowe zestawienie parametrów badań zamieszczono tabeli 2 .

Tabela 2. Parametry badań wykonanych w kolumnie rezonansowej

Table 2. Parameters of tests performed in resonant column

\begin{tabular}{|l|c|c|c|c|}
\hline \multirow{2}{*}{} & $\mathrm{p}^{\prime}$ & $\mathrm{V}_{\text {rod }}$ & napięcie & $\mathrm{f}_{\mathrm{r}}$ \\
\cline { 2 - 5 } & {$[\mathrm{kPa}]$} & {$[\mathrm{m} / \mathrm{s}]$} & {$[\mathrm{V}]$} & {$[\mathrm{Hz}]$} \\
\hline P11A & 45 & $8,25 \cdot 10^{-5}$ & $0,1-0,8$ & $202-180$ \\
\hline P11B & 85 & $8,25 \cdot 10^{-5}$ & $0,1-0,9$ & $200-182$ \\
\hline P11C & 100 & $8,25 \cdot 10^{-5}$ & $0,1-0,6$ & $205-185$ \\
\hline
\end{tabular}




\section{Analiza wyników badań}

W tabeli 3 zestawiono wyniki obliczeń początkowych modułów Younga $\left(\mathrm{E}_{0}\right)$ i odkształcenia postaciowego $\left(\mathrm{G}_{0}\right)$ według wzorów (3) i (4) uzyskane w badaniach trójosiowych. W kolumnie „, $\mathrm{E}_{0 \text { obl }}$ znajdują się wartości początkowego modułu odkształcenia $\left(\mathrm{E}_{0}\right)$ obliczone na podstawie wzorów (3) i (2) z pomiarów rzeczywistych prędkości fal podłużnych i poprzecznych; w kolumnie „, $\mathrm{E}_{0 z a ł}$ ” wartości uzyskane przez podstawienie do wzoru (3) współczynnika Poisson'a równego 0,5. Obliczony został również błąd względny dla początkowego modułu odkształcenia $\mathrm{E}_{0}$, który nie przekracza $1 \%$ (z wyjątkiem próbki P10). Wynika z tego, że przy pełnym nasyceniu porów gruntowych wodą, w warunkach bez odpływu, można przyjmować współczynnik Poisson'a jak dla ośrodka nieściśliwego.

Tabela 3. Zestawienie wyników obliczeń współczynnika Poisson’a i modułów odkształcenia uzyskane $\mathrm{z}$ badań $\mathrm{w}$ aparacie trójosiowym

Table 3. The calculation results of the Poisson's ratio and deformation modulus from triaxial tests

\begin{tabular}{|c|c|c|c|c|c|c|c|c|c|}
\hline & $\mathrm{p}^{\prime}$ & $\mathrm{V}_{\mathrm{s}}$ & $\mathrm{V}_{\mathrm{p}}$ & $\mathrm{v}$ & $\mathrm{G}_{0}$ & $\mathrm{E}_{0}$ obl & $\mathrm{E}_{0}$ zał & $\Delta \mathrm{E}_{0}$ & $\begin{array}{c}\text { Błąd } \\
\text { względny }\end{array}$ \\
\cline { 2 - 10 }$[\mathrm{kPa}]$ & {$[\mathrm{m} / \mathrm{s}]$} & {$[\mathrm{m} / \mathrm{s}]$} & {$[-]$} & {$[\mathrm{MPa}]$} & {$[\mathrm{MPa}]$} & {$[\mathrm{MPa}]$} & {$[\mathrm{MPa}]$} & {$[\%]$} \\
\hline P1 & 100 & 178 & 1588 & 0,49 & 62,73 & 187,40 & 188,20 & 0,80 & 0,43 \\
\hline P1 & 300 & 193 & 1494 & 0,49 & 73,75 & 220,01 & 221,26 & 1,25 & 0,57 \\
\hline P2 & 200 & 171 & 1607 & 0,49 & 58,19 & 173,90 & 174,57 & 0,67 & 0,38 \\
\hline P3 & 30 & 173 & 1380 & 0,49 & 61,06 & 182,19 & 183,17 & 0,97 & 0,54 \\
\hline P3 & 100 & 191 & 1386 & 0,49 & 74,42 & 221,82 & 223,26 & 1,44 & 0,65 \\
\hline P3 & 200 & 205 & 1391 & 0,49 & 85,73 & 255,29 & 257,19 & 1,90 & 0,75 \\
\hline P4 & 300 & 214 & 1622 & 0,49 & 88,84 & 264,96 & 266,53 & 1,57 & 0,59 \\
\hline P5 & 100 & 147 & 1569 & 0,50 & 42,14 & 126,04 & 126,41 & 0,37 & 0,30 \\
\hline P6 & 70 & 139 & 1539 & 0,50 & 37,48 & 112,14 & 112,45 & 0,31 & 0,27 \\
\hline P6 & 250 & 167 & 1559 & 0,49 & 54,10 & 161,69 & 162,31 & 0,63 & 0,39 \\
\hline P7 & 200 & 211 & 1687 & 0,49 & 82,81 & 247,11 & 248,43 & 1,32 & 0,53 \\
\hline P8 & 500 & 272 & 1661 & 0,49 & 147,97 & 439,83 & 443,90 & 4,08 & 0,93 \\
\hline P9 & 330 & 253 & 1635 & 0,49 & 129,94 & 386,63 & 389,81 & 3,19 & 0,82 \\
\hline P10 & 150 & 299 & 1740 & 0,49 & 200,26 & 594,68 & 600,77 & 6,09 & 1,02 \\
\hline
\end{tabular}

W literaturze spotyka się wartości współczynnika Poisson'a znacznie poniżej tych uzyskanych w badaniach w aparacie trójosiowym, ale odnoszą się one do różnego stopnia nasycenia gruntu wodą. Wartości współczynnika Poisson'a wzrastają wraz z stopniem nasycenia i zmniejszaniem się porowatości gruntu $[16,17,18]$.

$\mathrm{Z}$ badań w kolumnie rezonansowej otrzymano znacznie mniejsze wartości współczynnika Poisson'a w porównaniu z wynikami badań w aparacie trójosiowym z pomiarem prędkości fal. Różnice te wynikają z różnej metodyki badań: 
w aparacie trójosiowym prędkości fal sejsmicznych uzyskiwane są bezpośrednio w badaniu, natomiast w kolumnie rezonansowej wyliczane są pośrednio na podstawie drgań układu. Mimo zachowanych podobnych warunków badania (pełne nasycenie próbki, warunki bez odpływu) wartości współczynnika Poisson'a uzyskane z badań w kolumnie rezonansowej mogą być nawet o $50 \%$ mniejsze od tych uzyskanych w aparacie trójosiowym.

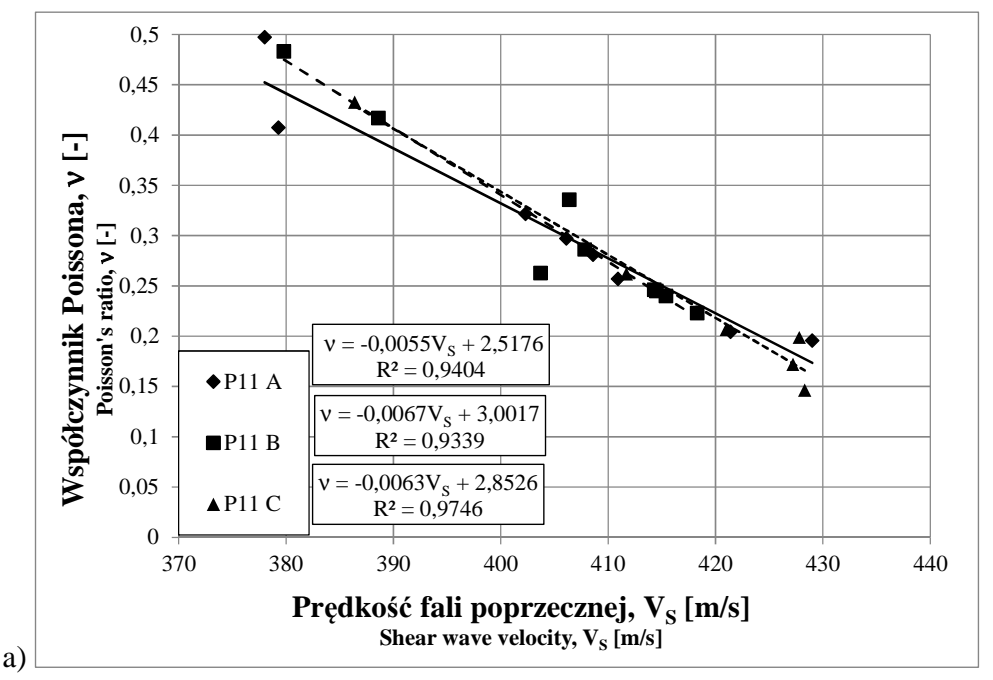
Shear wave velocity, $V_{S}[\mathrm{~m} / \mathrm{s}]$

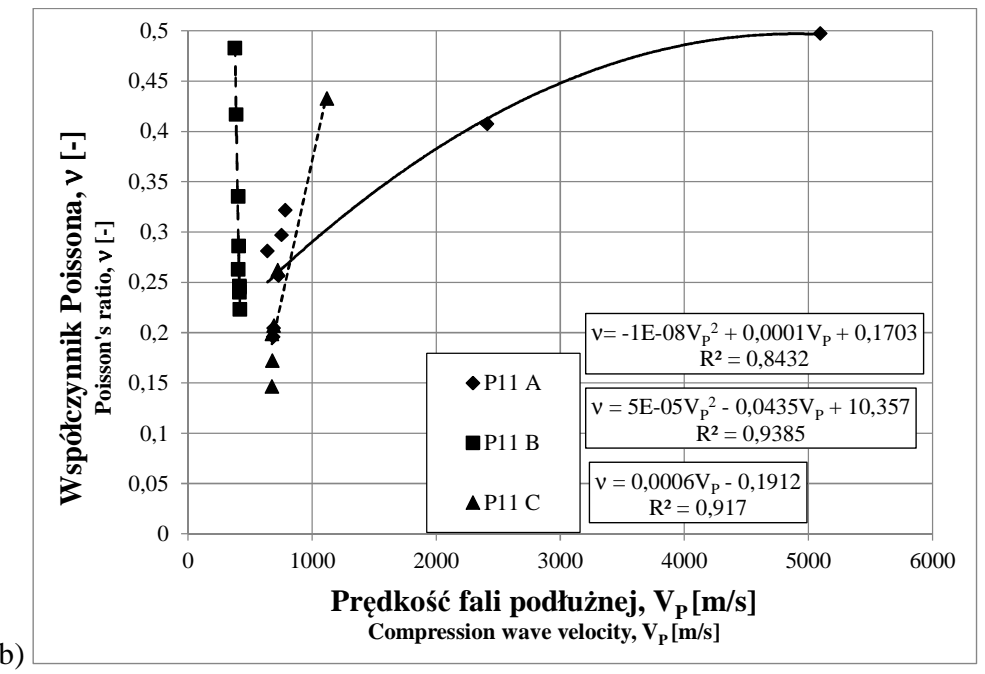

Rysunek 2. Zależność współczynnika Poisson'a i prędkości fali a) poprzecznej, b) podłużnej uzyskany w badaniach w kolumnie rezonansowej

Figure 2. The correlation between the Poisson's ratio and a) shear, b) compression wave velocity from the resonant column tests 
Prędkości fali poprzecznej $\left(\mathrm{V}_{\mathrm{s}}\right)$ obliczone $\mathrm{z}$ badań w kolumnie rezonansowej są większe niż te uzyskane z pomiarów z zastosowaniem piezoelementów. Podobnie, prędkości fali podłużnej w ograniczonym medium $\left(\mathrm{V}_{\text {rod }}\right) \mathrm{z}$ kolumny rezonansowej wydają się zbyt duże, w porównaniu z prędkościami fal podłużnych $\left(\mathrm{V}_{\mathrm{p}}\right)$ uzyskiwanymi z badań sejsmicznych w gruntach [19]. Może to być jednak spowodowane innym rodzajem badanego materiału (np. większą zawartością frakcji piaskowej w gruncie badanym w kolumnie rezonansowej).

Wartości współczynnika Poisson'a $\left(v_{\text {dyn }}\right)$ maleją liniowo $z$ wzrostem prędkości fali poprzecznej $\left(\mathrm{V}_{\mathrm{s}}\right)$; w przypadku fali podłużnej $\left(\mathrm{V}_{\mathrm{p}}\right)$ takiej zależności nie zaobserwowano (rys. 2).

\section{Podsumowanie i wnioski}

Z przeprowadzonych badań wypływają następujące wnioski:

- z badań w aparacie trójosiowym otrzymuje się większe wartości współczynnika Poisson'a niż z badań w kolumnie rezonansowej (przy takich samych warunkach badania: ośrodek całkowicie nasycony wodą, brak możliwości odpływu wody z porów gruntowych, stałe ciśnienie wody w porach i w komorze, niezmienne warunki badania);

- wartości współczynnika Poisson'a z badań w aparacie trójosiowym są zbliżone do wartości właściwych ośrodkom nieściśliwym; wynika to z warunków samego badania; ewentualne oddziaływania $w$ takich warunkach przejmowane są przez wodę w postaci wygenerowanej nadwyżki ciśnienia wody w porach;

- na potrzeby szacowania sztywności początkowej gruntu przy pełnym nasyceniu porów gruntowych wodą, w warunkach bez odpływu, można przyjmować współczynnik Poisson'a równy 0,5 jak dla ośrodka nieściśliwego,

- wartości współczynnika Poisson'a maleją ze wzrostem prędkości fali, zarówno poprzecznej $\left(\mathrm{V}_{\mathrm{s}}\right)$ jak i podłużnej $\left(\mathrm{V}_{\mathrm{p}}\right)$, przy czym trend dla prędkości fali poprzecznej jest bardziej wyraźny;

- ze względu na pośredni charakter otrzymywania prędkości fal z kolumny rezonansowej wydaje się, że do szacowania wartości dynamicznego współczynnika Poisson'a $\left(v_{\text {dyn }}\right)$ korzystniejsze jest stosowanie w obliczeniach prędkości fal podłużnych i poprzecznych uzyskanych z bezpośrednich pomiarów.

Należy również pamiętać, że istnieją różnice w wartościach współczynnika Poisson'a wyznaczanych jako „statyczne” i „dynamiczne” [2]. Kolejnym krokiem powinno być zatem poszukiwanie zależności pomiędzy „statycznym” i ,dynamicznym” współczynnikiem Poisson'a w gruntach oraz ustalenie wpływu stopnia nasycenia gruntu na wartości współczynnika Poisson'a.

Badania zaprezentowane $\mathrm{w}$ pracy zostały częściowo sfinansowane z projektu NCN (nr um. 0467/B/T02/2011/40). 


\section{Literatura}

[1] Essien U.E., Akankpo A.O., Igboekwe M.U. 2014. Poisson's Ratio of Surface Soils and Shallow Sediments Determined from Seismic Compressional and Shear Wave Velocities. International Journal of Geosciences, 5, 1540-1546.

[2] Zhang J.J., Bentley L.R. 2005. Factors determining Poisson's ratio. CREWES Research Report - Volume 172005.

[3] Sas W., Gabryś K., Soból E., Szymański A. 2016. Dynamic Characterization of Cohesive Material Based on Wave Velocity Measurements. Applied Sciences, 6(2), 49; doi:10.3390/app6020049.

[4] Viggiani G., Atkinson J.H. 1995. Interpretation of bender element tests. Geotechnique 45, No. 1, 149 - 154, Technical Note.

[5] Markowska-Lech K., Lech M., Bajda M., Szymański A. 2013 Small strain stiffness in overconsolidated Pliocene clays. Annals of Warsaw University of Life Sciences SGGW Land Reclamation No 45 (2), 2013: 169-181.

[6] Markowska-Lech K., Lech M., Bajda M., Szymański A. 2008. The use of seismic tests for determination of shear modulus in cohesive soils. EJPAU 11(2), \#20.

[7] Tymiński, W., Markowska-Lech, K. 2005. Kryteria pomiaru prędkości fali poprzecznej w gruntach spoistych. Materiały konferencyjne, 51 Konferencja Naukowa Komitetu Inżynierii Lądowej i Wodnej PAN i Komitetu Nauki PZITB, Krynica, t. IV, 65-72.

[8] Pineda J.A., Colmenares J.E., Hoyos L.R. 2014. Effect of fabric and Weathering Intensity on Dynamic properties of Residual and Saprolitic Soils via Resonant Column Testing. Geotechnical Testing Journal, 37, 5, 800-816.

[9] Markowska-Lech K. 2008. The determination of shear modulus in overconsolidated cohesive soils. Foundations of Civil and Environmental Engineering, Poznan University of Technology, 12, 61-71.

[10] Hasan, A.M., Wheeler, S.J. 2015. Measuring travel time in bender/extender element tests. In Proceedings of the 16th ECSMGE Geotechnical Engineering for Infrastructure and Development, Edinburg, UK, 13-17 September 2015; 3171-3176.

[11] Styler, M.A., Howie, J.A. 2014. Continuous Monitoring of Bender Element Shear Wave Velocities During Triaxial Testing. Geotechnical Testing Journal. 37, 218-230.

[12] Soból E., Sas W. i Szymański A. 2015. Zastosowanie kolumny rezonansowej do określenia reakcji gruntów drobnoziarnistych obciążonych dynamicznie. Przegląd Naukowy - Inżynieria i Kształtowanie Środowiska, 68, 133-144.

[13] Gabryś K., Sas W. i Szymański A. 2013. Kolumna rezonansowa jako urządzenie do badań dynamicznych gruntów spoistych. Przegląd Naukowy - Inżynieria i Kształtowanie Środowiska, 59, 3-13.

[14] Sas W. i Gabryś K. 2012. Laboratory measurement of shear stiffness in resonant column apparatus. Acta Scientiarum Polonorum, series Architectura, 11(4), 29-39.

[15] Sas W., Gabryś K. i Szymański A. 2013. Determination of Poisson's ratio by means of resonant column tests. Electronic Journal of Polish Agricultural Universities: EJPAU, 16, 3, Topic: Civil Engineering. 
[16] Sawangsuriya A., Fall M., Fratta D. 2008. Wave-Based Techniques for Evaluating Elastic Modulus and Poisson's Ratio of Laboratory Compacted Lateritic Soils. Geotech Geol Eng (2008) 26:567-578.

[17] Di Benedetto H., Geoffroy H., Duttine A., Sauzéat C., Chau B. Comportement anisotrope des sols et caractérisation d'un site à partir d'essais de propagation d'ondes.

[18] Amaral M.F., Viana da Fonseca A. i Carvalho J. 2011. Dynamic Poisson ratio analysis. Proceedings of the 15th European Conference on Soil Mechanics and Geotechnical Engineering. A. Anagnostopoulos et al. (Eds.) IOS Press. 1, 115-120.

[19] Mayne P.W. 2001. Stress-strain-strength-flow parameters from enhanced in-situ tests. Proceedings of International Conference on In-Situ Measurement of soil Properties\&Case Histories, Bali, Indonesia, 27-48.

\section{THE ESTIMATION OF POISSON'S RATIO BASED ON SEISMIC WAVE VELOCITY}

\section{S u m m a r y}

Poisson's ratio as one of the parameters characterizing the material deformation is widely used in geophysics and it is based on shear and compressional wave velocities. On the other hand, in the geotechnical laboratories a lot of tests using mechanical waves velocities on soils are performed, so Authors have attempted to transfer the elasticity theory on soils and determine the Poisson's ratio. The paper presents the values of Poisson's ratio obtained for natural cohesive soils with two different techniques: the triaxial tests using bender elements (BE) and resonant column (RC).

Keywords: piezoelements, shear wave velocity, compressional wave velocity, resonant column, Poisson's ratio, cohesive soils

Przestano do redakcji: 07.06.2016 $r$.

Przyjęto do druku: 30.06 .2016 r.

DOI: $10.7862 / \mathrm{rb} .2016 .65$ 